\title{
PENERAPAN FUZZY DALAM MENENTUKAN DAMPAK PENGGUNA SMARTPHONE DI KALANGAN MASYARAKAT
}

\author{
Winda Permata Sari ${ }^{1}$, Winda Lidyasari ${ }^{2}$, Muhammad Fachrur Rozi ${ }^{3}$, Yulia Andini ${ }^{4}$, Agus Perdana Windarto ${ }^{5}$ \\ SistemInformasi, STIKOM Tunas Bangsa Pematangsiantar

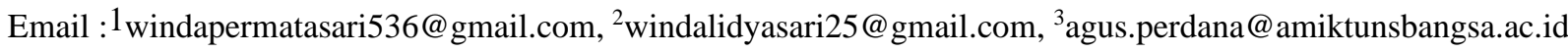

\begin{abstract}
Abstrak
Penelitian ini bertujuan untuk menentukan dampak pengguna smartphone dikalangan masyarakat. Smartphone juga mempunyai kemampuan disetiap fitur-fiturnya yang mampu membantu atau memenuhi kebutuhan penggunanya. Smartphone sudah menjadi bagian dari gaya hidup setiap orang, mulai dari anak-anak, remaja, maupun dewasa. Banyak orang tidak menyadari bahwa dalam menggunakan smartphone memiliki dampak yang berpengaruh bagi penggunanya baik secara internal maupun eksternal. Dalam menentukan dampak pengguna smartphone dikalangan masyarakat, perlu adanya sistem pendukung, sistem pendukung yang digunakan yaitu metode Fuzzy Tsukamoto, dalam metode Fuzzy Tsukamoto penulis menggunakan 4 variabel yaitu jarak, pengguna, waktu dan dampak untuk menentukan dampak pengguna smartphone.
\end{abstract}

Kata Kunci : Smartphone, Fuzzy

\begin{abstract}
This study aims to determine the impact of smartphone users among the community. Smartphones also have the ability in each of its features that can help or meet the needs of its users. Smartphones have become a part of everyone's lifestyle, ranging from children, adolescents, and adults. Many people do not realize that using a smartphone has an impact on users both internally and externally. In determining the impact of smartphone users among the public, there needs to be a support system, a support system used is the Fuzzy Tsukamoto method, in the Fuzzy Tsukamoto method the writer uses 4 variables namely distance, user, time and impact to determine the impact of smartphone users.
\end{abstract}

Keywords : Smartphone, Fuzzy

\section{PENDAhUluAN}

Perkembangan teknologi informasi, terutama smartphone menjadi semakin pasif diberbagai kalangan baik itu anak-anak, remaja, maupun dewasa, dan smartphone sudah menjadi bagian dari gaya hidup bagi setiap orang. Smartphone atau ponsel cerdas merupakan telepon genggam yang mempunyai kemampuan disetiap fitur-fitur yang disediakan oleh smartphone tersebut yang mampu membantu atau memenuhi kebutuhan setiap penggunanya. Fiturfitur yang ada pada smartphone tidak hanya digunakan untuk mengirim pesan atau telepon. Smartphone dapat digunakan sebagai media pembelajaran media untuk bersilaturahmi, media bisnis, media menyalurkan bakat, dan lainlain dengan menggunakan fitur-fitur yang mendukung dismartphone tersebut.

Smartphone sudah menjadi bagian dari gaya hidup bagi setiap orang. Sering kali kita jumpai orang-orang yang begitu lengket dengan smartphone mereka, dan banyak orang tidak menyadari bahwa dalam menggunakan smartphone memiliki suatu dampak yang berpengaruh bagi penggunanya, baik itu secara internal maupun ekternal. Dampak internal yaitu dampak yang terjadi pada pengguna seperti acuh pada waktu maupun kesehatannya. Dampak ekternal yaitu dampak yang mengakibatkan pengguna menjadi acuh terhadap lingkungan dan orang-orang sekitar karena terlalu fokusnya memainkan smartphonenya, mereka yang menggunakan smartphone akan banyak menghabiskan waktu untuk menatap layar gadgetnya dibandingkan berinteraksi dengan orang sekitarnya, dan bagi mereka yang menggunakan smartphone terlalu lama atau melampaui batas maksimal penggunaan smartphone akan membuat kesehatan seseorang menurun serta menyebabkan kerusakan pada kesehatan mata yang terus- menerus terpapar sinar biru dari gadget yang digunakan pengguna.

Smartphone atau ponsel cerdas memberikan kemudahan yang diberikan melalui fitur-fitur yang ada disetiap smartphone, tidak sedikit kalangan masyarakat yang ingin memiliki smartphone tersebut. Namun sekarang hampir disemua kalangan baik itu dari kalangan bawah hingga kalangan atas, dewasa maupun anak-anak sudah memiliki smartphone, karena smartphone memberikan fitur yang mampu membantu setiap pekerjaan atau pun memberikan informasi dan smartphone mampu membuat jarak yang jauh menjadi dekat dengan mengunakan media online.

Peningkatan dari logika Boolean yang berhadapan dengan konsep kebenaran sebagian. Saat logika klasik menyatakan bahwa segala hal dapat diekspresikan dalam istilah biner (0 atau 1, hitam atau putih, ya atau tidak), logika fuzzy menggantikan kebenaran Boolean dengan tingkat kebenaran. Pada metode tsukamoto setiap konsekuensi pada aturan yang berbentuk IF- THEN harus direpresentasikan dengan suatu himpunan fuzzy dengan fungsi keanggotaan yang monoton. Sebagai hasilnya, output hasil inferensi dari tiap-tiap aturan diberikan secara tegas (crisp) hasil akhirnya diperoleh dengan menggunakan rata-rata bobot. Metode defuzifikasi (penegasan). Metode defuzifikasi yang digunakan dalam metode Tsukamoto adalah metode defuzifikasi rata-rata terpusat (Center Average Defuzzyfier)[1]

\section{TEORITIS}

\subsection{LogikaFuzzy}


Logika adalah ilmu yang mempelajari secara sistematis aturan-aturan penalaran yang absah (valid) (Frans Susilo, 2006). Logika yang biasa dipakai dalam kehidupan sehari-hari maupun dalam penalaran ilmiah adalah logika dwi nilai, yaitu logika yang setiap pernyataan mempunyai dua kemungkinan nilai, yaitu benar atau salah. Asumsi dasar dalam logika dwi nilai, yakni bahwa setiap proporsi hanya mempunyai dua nilai kebenaran tersebut[2]

\subsection{Metode Tsukamoto}

Metode Tsukamoto adalah aturan yang berbentuk IF-THEN harus direpresentasikan dengan suatu himpunan fuzzy dengan fungsi keanggotan monoton. Sebagai hasilnya, output hasil inferensi dari tiap-tiap aturan diberikan secara tegas (crisp) berdasarkan $\alpha$-predikat (fire strength). Hasil akhir menggunakan rata- rata terbobot bentuk model fuzzy Tsukamoto adalah :

IF (X IS A) and (Y IS B) Then (Z IS C)

Dimana A,B dan C adalah himpunan fuzzy.

Misalkan diketahui 2 rule berikut .

IF ( $\mathrm{X}$ is A1) AND ( $\mathrm{Y}$ is B1) THEN ( $\mathrm{Z}$ is $\mathrm{C} 1$ )

IF ( $\mathrm{X}$ is $\mathrm{A} 2$ ) AND ( $\mathrm{Y}$ is B2) THEN ( $\mathrm{Z}$ is $\mathrm{C} 2$ )

Dalam inferensinya, metode tsukamoto menggunakan tahapan berikut ;

1. Fuzzyfikasi

2. Pembentukan basis pengetahuan Fuzzy ( Rule dalam bentuk IF....THEN)

3. Mesin Inferensi, menggunakan fungsi implikasi MIN untuk mendapatkan nilai $\alpha$-predikat tiap-tiap rule $(\alpha 1, \alpha 2$, $\alpha 3, \ldots \ldots \alpha n)$. Kemudian masing-masing nilai $\alpha$-predikat ini digunakan untuk menghitung keluaran hasil inferensi secara tegas (crisp) masing rule (z1, z2, z3,....zn)

4. Defuzzyfikasi menggunakan metode rata-rata (Average)

$Z=\frac{\sum \alpha_{1} Z_{1}}{\sum \alpha_{1}}$

Keterangan :

$\mathrm{Z}=$ Variabel

output $\alpha \mathrm{i}=$ Nilai $\alpha$

predikat $\mathrm{zi}=$ Nilai variabel

output masing-masing dari aturan implikasi Gambar 2

Menunjukkan skema penalaran fungsi implikasi MIN dan proses defuzzifikasi dilakukan dengan cara mencari nilai rata- ratanya.[2]

Proses Defuzzifikasi hasil akhir output (z) diperoleh dengan menggunkan rata-rata pembobotan[2].

$Z=\frac{\alpha_{1} Z_{1}+\alpha_{2} Z_{2}+\cdots . .+\alpha_{n} Z_{n}}{\alpha_{1}+\alpha_{2}+\cdots+\alpha_{n}}$

\subsection{Cara Kerja Logika Fuzzy}

Untuk memahami cara kerja logika fuzzy, perhatikan struktur elemen dasar sistem inferensi fuzzy pada gambar 1 berikut: [2]

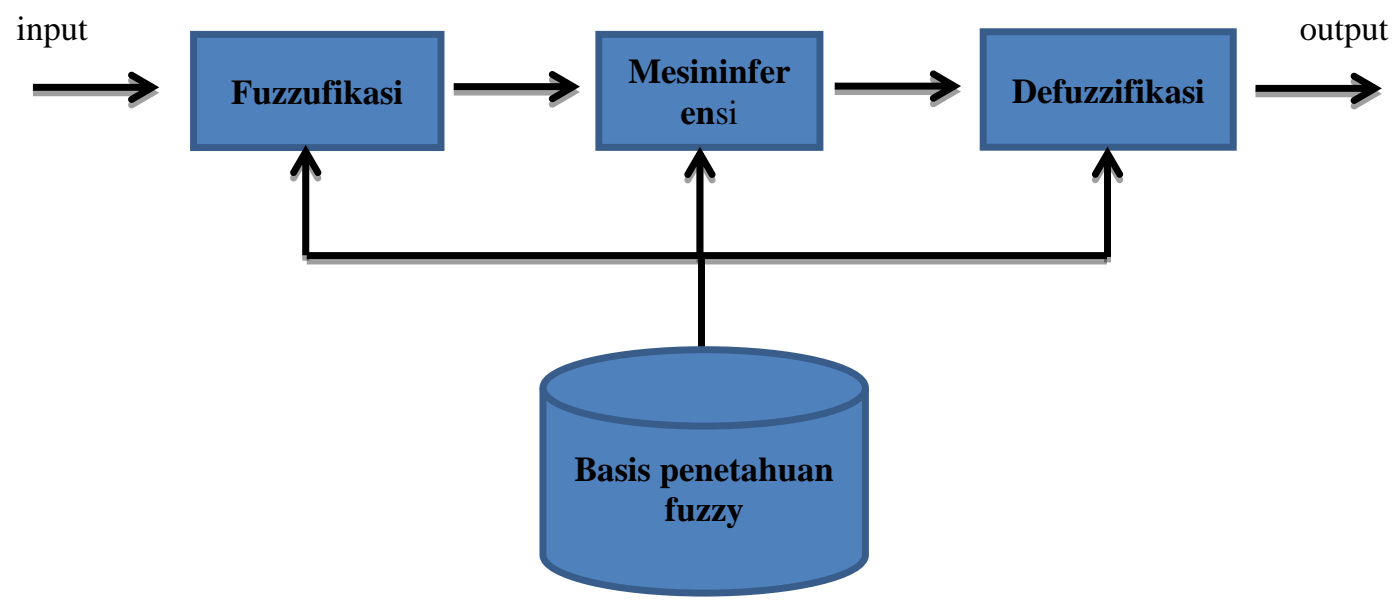

Gambar 1. Struktur system inferensi fuzzy

Keterangan : 
1. Basis pengetahuan fuzzy

Kumpulan rule-rule fuzzy dalam bentuk pernyataan IF....THEN

2. Fuzzyfikasi

Proses untuk mengubah nilai input sistem yang mempunyai nilai tegas menjadi variabel linguistic menggunakan fungsi keanggotaan yang disimpan dalam basis pengetahuan fuzzy.

3. Mesin Inferensi

Proses untuk mengubah input fuzzy menjadi output fuzzy dengan cara mengikuti aturan-aturan (IF-THEN rules) yang telah ditetapkan pada basis pengetahuan fuzzy

4. Defuzzyfikasi

Mengubah output fuzzy yang diperoleh dari mesin inferensi menjadi nilai tegas menggunakan fungsi keanggotaan yang sesuai dengan saat dilakukan fuzzyfikasi

\section{METODE PENELITIAN}

\subsection{Tahapan -Tahapan Penelitian}

Tahapan yang digunakan dalam penelitian adalah :

1. Pemilihan Jenis Data

Penelitian ini bersifat kuantitatif merupakan salah satu jenis penelitian yang spesifikasinya adalah sistematis, terencana dan terstruktur dengan jelas sejak awal hingga pembuatan desain penelitiannya.

2. Tahapan Penggumpulan Data Adapun teknik dan mengumpulkan data yang diperoleh dari penyebaran kuisoner dikota PemangSiantar dan mengamati setiap pengguna smartphone yang ada dilingkungan kita.

3. Analisis Pengolahan Data

Data yang telah diperoleh akan diolah terlebih dahulu. Pada tahap pengolahan data ini, data akan dihitung sesuai dengan ketentuan fuzzy tsukamoto sehingga menghasilkan output secara tegas (crisp).

\section{HASIL DAN PEMBAHASAN}

Penyelesaian masalah untuk kasus dalam menentukan dampak pengguna smartphone di kalangan masyarakat, adalah sebagai berikut :

Table 1.Himpunan Fuzzy Dampak Pengguna Smartphone

\begin{tabular}{llll}
\hline Fungsi & Variabel fuzzy & Fuzzy set & Domain \\
\hline Input & Jarak & Dekat & \\
& & Normal & {$[1,3,6]$} \\
& & Jauh & \\
& Pengguna & Anak-anak & \\
& & Remaja & {$[2,5,6]$} \\
& & Dewasa & \\
& Waktu & Sebentar & \\
& & Normal & {$[2,5,7]$} \\
& & Lama & \\
Output & Dampak & Baik & {$[5,10]$}
\end{tabular}

Siapakah pengguna paling banyak diantara anak-anak, remaja dan dewasa, jika jarak $=5$, pengguna $=6$, dan waktu $=$ 6.? Dalam menentukan dampak penggunaan smartphone dikalangan masyarakat menggunakan 9 aturan fuzzy sebagai berikut :

[R1] IF Jarak DEKAT and Pengguna ANAK-ANAK and Waktu SEBENTAR, THEN Dampak BAIK

[R2] IF Jarak DEKAT and Pengguna REMAJA and Waktu NORMAL, THEN Dampak BAIK

[R3] IF Jarak DEKAT and Pengguna DEWASA and Waktu LAMA, THEN Dampak BURUK

[R4] IF Jarak NORMAL and Pengguna ANAK-ANAK and Waktu SEBENTAR, THEN Dampak BAIK

[R5] IF Jarak NORMAL and Pengguna REMAJA and Waktu NORMAL, THEN Dampak BAIK

[R6] IF Jarak NORMAL and Pengguna DEWASA and Waktu LAMA, THEN Dampak BURUK 
[R7] IF Jarak JAUH and Pengguna ANAK-ANAK and Waktu SEBENTAR, THEN Dampak BURUK

[R8] IF Jarak JAUH and Pengguna REMAJA and Waktu NORMAL, THEN Dampak BAIK

[R9] IF Jarak JAUH and Pengguna DEWASA and Waktu LAMA, THEN Dampak BURUK

\subsection{Sistem Inferensi Fuzzy untuk data Jarak (A)}

Variable jarak, terbagi menjadi 3 himpunan fuzzy yaitu dekat,normal dan jauh.

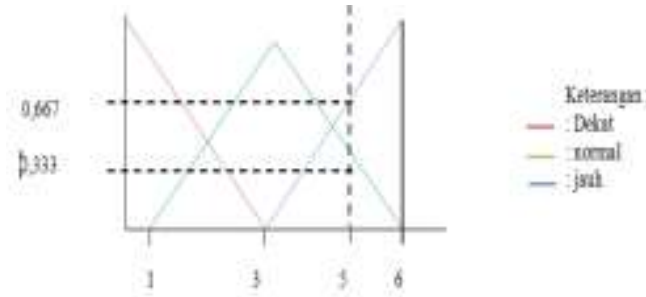

Gambar2. himpunan fuzzy untuk data jarak

$\mu_{\mathrm{A}(\mathrm{Normal})}=\frac{\mathrm{c}-\mathrm{x}}{\mathrm{c}-\mathrm{b}}=\frac{6-}{6-3}=\frac{-}{3}=0,333$

$\mu_{\mathrm{A}(\text { jauh })}=\frac{\mathrm{x}-\mathrm{b}}{\mathrm{c}-\mathrm{b}}=\frac{5-3}{6-3}=0,667$

$\mu_{\mathrm{A}(\text { dekat })}=0$

\subsection{Sistem Inferensi Fuzzy untuk data Pengguna (B)}

Variabel pengguna, terbagi menjadi 3 himpunan fuzzy yaitu anak-anak, remaja, dan dewasa.

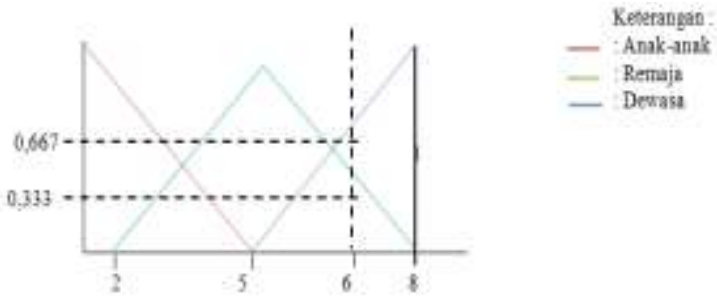

Gambar3. himpunan fuzzy untuk data pengguna

$\mu_{\mathrm{B}(\text { dewasa })}=\frac{\mathrm{x}-\mathrm{b}}{\mathrm{c}-\mathrm{b}}=\frac{6-5}{8-5}=\frac{1}{3}=0,333$

$\mu_{\mathrm{B}(\text { Remaja })}=\frac{\mathrm{c}-\mathrm{x}}{\mathrm{c}-\mathrm{b}}=\frac{8-6}{8-5}=\frac{2}{3}=0,667$

$\mu_{\mathrm{B}(\text { Anak-anak })}=0$

\subsection{Sistem Inferensi Fuzzy untuk data Waktu(A)}

Variabel waktu, terbagi menjadi 3 himpunan fuzzy yaitu sebentar, normal, dan lama.

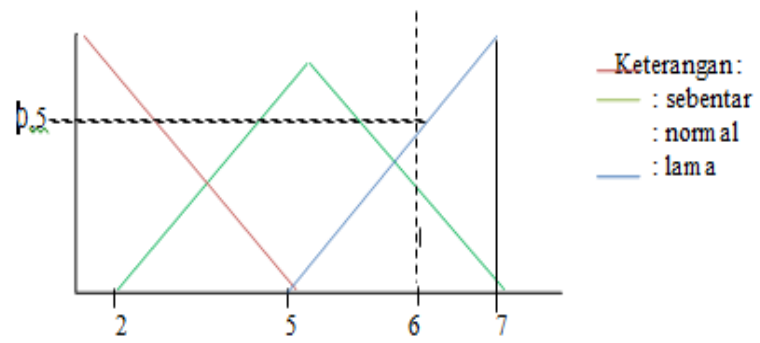

Gambar4. himpunan fuzzy untuk data waktu

$\mu_{\mathrm{C}(\text { lama })}=\frac{\mathrm{x}-\mathrm{b}}{\mathrm{c}-\mathrm{b}}=\frac{6-5}{7-5}=\frac{1}{2}=0,5$
$\mu_{\mathrm{C} \text { (Normal) }}=\frac{\mathrm{c}-\mathrm{x}}{\mathrm{c}-\mathrm{b}}=\frac{7-6}{7-5}=\frac{1}{2}=0,5$
$\mu_{\mathrm{C} \text { (sebentar) }}=0$

\subsection{Penghitungan Rule}

[R1] IF Jarak DEKAT and Pengguna ANAK-ANAK and Waktu SEBENTAR, THEN Dampak BAIK 


$$
\begin{aligned}
& \begin{aligned}
\mathrm{Z}_{\text {(baik) }} & =\min \left(\alpha_{\mathrm{A}(\text { dekat })} ; \alpha_{\mathrm{B}(\text { anak-anak })} ; \alpha_{\mathrm{c}(\text { sebentar })}\right. \\
& =\min (0 ; 0 ; 0) \\
& =0\left(\alpha_{1)}\right. \\
& \mathrm{b}-\mathrm{x} \\
\mathrm{Z}_{\text {(baik) }} & \mathrm{b}-\mathrm{a}
\end{aligned} \\
& 0=\frac{10-\mathrm{x}}{10-5} \\
& 10-\mathrm{x}=0 \times 10-5 \\
& 10-\mathrm{x}=-5 \\
& -\mathrm{x}=-5-10 \\
& \mathrm{x}=15
\end{aligned}
$$

[R2] IF Jarak DEKAT and Pengguna REMAJA andWaktu NORMAL, THEN Dampak BAIK

$Z_{(\text {baik })}=\min \left(\alpha_{A(\text { dekat })} ; \alpha_{B(\text { remaja })} ; \alpha_{c(\text { normal })}\right.$$$
=\min (0 ; 0,666 ; 0,5)
$$$$
=0\left(\alpha_{2}\right)
$$$$
Z_{(\text {baik })}=\frac{b-x}{b-a}
$$$$
0=\frac{10-x}{10-5}
$$$$
10-x=0 \times 10-5
$$$$
10-\mathrm{x}=-5
$$$$
-x=-5-10
$$$$
\mathrm{x}=15
$$

[R3] IF Jarak DEKAT and Pengguna DEWASA and Waktu LAMA, THEN Dampak BURUK

$$
\begin{aligned}
& \mathrm{Z}_{\text {(buruk) }}=\min \left(\alpha_{\mathrm{A} \text { (dekat) }} ; \alpha_{\mathrm{B} \text { (dewasa) }} ; \alpha_{\mathrm{c}(\text { lama })}\right. \\
& =0\left(\alpha_{3}\right) \\
& \mathrm{Z}_{\text {(buruk) }}=\frac{\mathrm{x}-\mathrm{a}}{\mathrm{b}-\mathrm{a}} \\
& 0=\frac{x-5}{10-5} \\
& \mathrm{x}-5=0 \times 10-5 \\
& \mathrm{x}-5=-5 \\
& x=-5+5 \\
& \mathrm{X}=0
\end{aligned}
$$$$
=\min (0 ; 0,333 ; 0,5)
$$

[R4] IF Jarak NORMAL and Pengguna ANAK-ANAK and Waktu SEBENTAR, THEN Dampak BAIK

$$
\begin{aligned}
& \begin{aligned}
\mathrm{Z}_{\text {(baik) }} & =\min \left(\alpha_{\mathrm{A}(\text { normal })} ; \alpha_{\mathrm{B}(\text { anak-anak })} ; \alpha_{\mathrm{c}(\text { sebentar })}\right. \\
& =\min (0,333 ; 0 ; 0) \\
& =0\left(\alpha_{4}\right) \\
\mathrm{Z}_{\text {(baik) }} & =\frac{\mathrm{b}-\mathrm{x}}{\mathrm{b}-\mathrm{a}}
\end{aligned} \\
& 0=\frac{10-\mathrm{x}}{10-5} \\
& 10-\mathrm{x}=0 \times 10-5 \\
& 10-\mathrm{x}=-5- \\
& \mathrm{x}=-5-10 \\
& \mathrm{x}=15
\end{aligned}
$$

[R5] IF Jarak NORMAL and Pengguna REMAJA and Waktu NORMAL, THEN Dampak BAIK

$\mathrm{Z}_{(\text {baik })}=\min \left(\alpha_{\mathrm{A}(\text { normal })} ; \alpha_{\mathrm{B}(\text { remaja })} ; \alpha_{\mathrm{c}(\text { normal })}\right.$$$
=\min (0,333 ; 0,666 ; 0,5)
$$$$
=0,333\left(\alpha_{5}\right)
$$$$
\mathrm{Z}_{\text {(baik) }}=\frac{\mathrm{b}-\mathrm{x}}{\mathrm{b}-\mathrm{a}}
$$$$
0,333=\frac{10-x}{10-5}
$$$$
10-\mathrm{x}=0,333 \times 5
$$$$
10-\mathrm{x}=1,665
$$$$
-\mathrm{x}=1,666-10
$$$$
\mathrm{x}=8,335
$$

[R6] IF Jarak NORMAL and Pengguna DEWASA and Waktu LAMA, THEN Dampak BURUK 


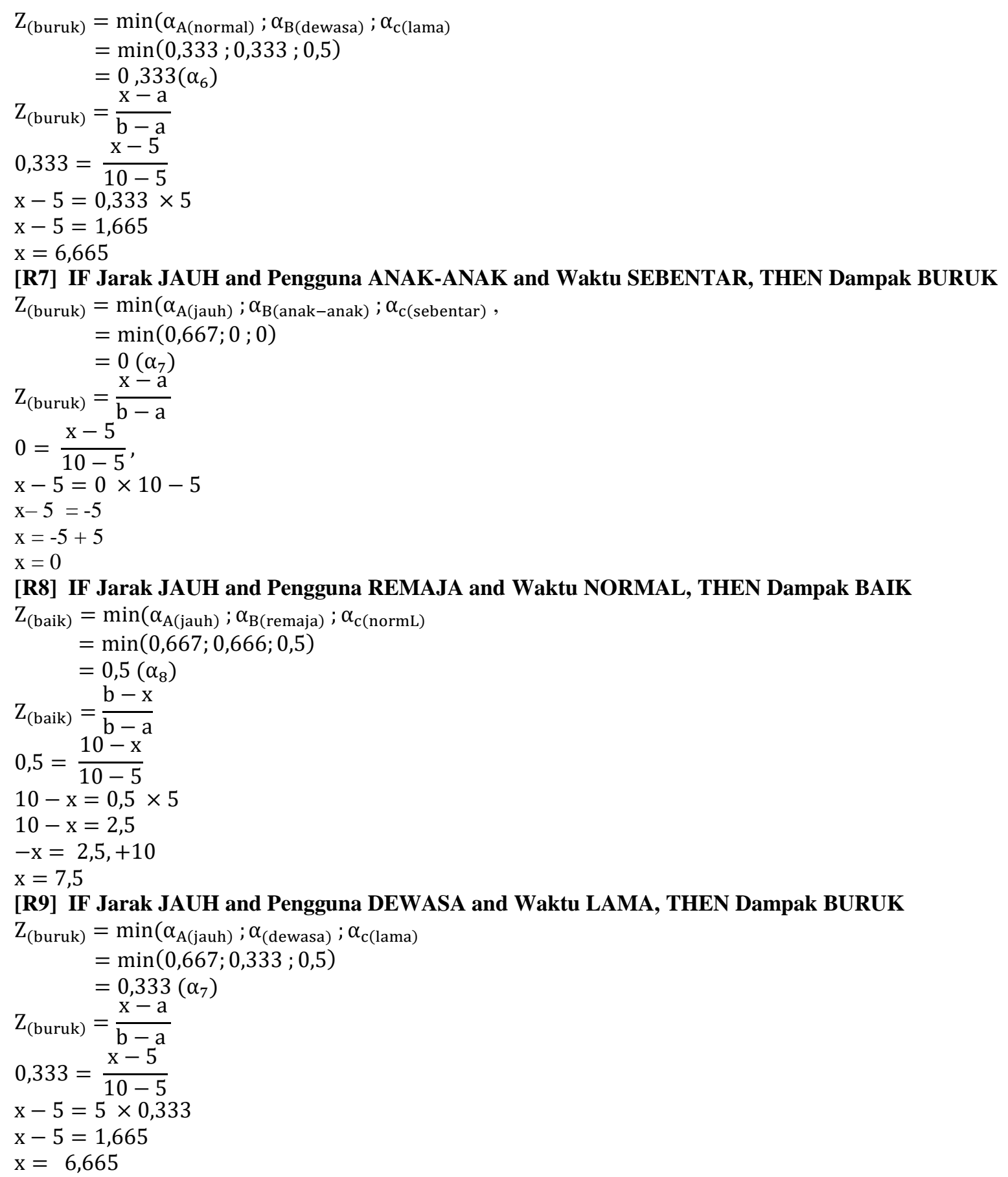

\subsection{Penghitungan Nilai Rata-rata}

$$
\begin{gathered}
\mathrm{X}=\frac{\left(\mathrm{Z}_{1} \times \alpha_{1}\right)+\left(\mathrm{Z}_{2} \times \alpha_{2}\right)+\left(\mathrm{Z}_{3} \times \alpha_{3}\right)+\left(\mathrm{Z}_{4} \times \alpha_{4}\right)+\left(\mathrm{Z}_{5} \times \alpha_{5}\right)}{\left(\mathrm{Z}_{6} \times \alpha_{6}\right)+\left(\mathrm{Z}_{7} \times \alpha_{7}\right)+\left(\mathrm{Z}_{8} \times \alpha_{8}\right)+\left(\mathrm{Z}_{9} \times \alpha_{9}\right)} \\
\begin{array}{c}
\alpha_{1}+\alpha_{2}+\alpha_{3}+\alpha_{4}+\alpha_{5}+\alpha_{6}+\alpha_{7}+\alpha_{8}+\alpha_{9} \\
(0 \times 15)+(0 \times 15)+(0 \times 0)+(0 \times 15)+(0,333 \times 8,335)+(0,333 \times 6,665) \\
0+(0 \times 0)+(0,5 \times 7,5)+(0,333 \times 6,665)
\end{array} \\
\mathrm{X}=\frac{+0+0+0+0,333+0,333+0+0,5+0,333}{1,499} \\
\mathrm{X}=7,314
\end{gathered}
$$

\section{KESIMPULAN}

Berdasarkan hasil penelitian dan pembahasan maka dapat disimpulkan sebagai berikut: 
1. Fuzzy tsukamoto dapat diterapkan dalam menetukan dampak pengguna smartphone dikalangan masyarakat.

2. Dengan memanfaatkan metode fuzzy tsukamoto, dapat membantu dalam menentukan keputusan dan mentukan berapa banyak pengguna, dan dampak dari penggunaan smartphone.

3. Pada penerapannya fuzzy tsukamoto dapat membantu menentukan pengguna anak-anak,remaja,dan dewasa dalam jangka waktu tertentu sehingga dapat menghasilkan dampak dari variabel pengguna, waktu, jarak, dan dampak.

\section{DAFTAR PUSTAKA}

[1] Kemal Farouq Mauladi, "Penentuan Jumlah Produksi Sarung Tenun Tradisional dengan Metode Fuzzy Tsukamoto Kemal," SMATIKA J. Vol., vol. 07, no. 1, p. 21, 2017.

[2] Fajriana, Safwandi, and A. Prama, "'Implementasi Fuzzy Tsukamoto Dalam Penentuan Produksi Beras Di Kilang Padi Peumakmu Gampong Aceh Utara,’” Univ. Malikussaleh, pp. 1-8, 2013. 